\title{
Genome-wide identification of WRKY family genes and their response to cold stress in Vitis vinifera
}

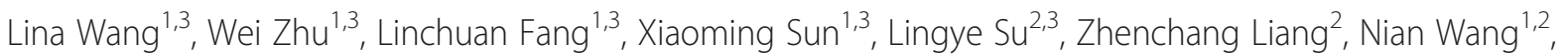
Jason P Londo ${ }^{4}$, Shaohua Li $\mathrm{Li}^{1,2^{*}}$ and Haiping Xin ${ }^{1,2^{*}}$

\begin{abstract}
Background: WRKY transcription factors are one of the largest families of transcriptional regulators in plants. WRKY genes are not only found to play significant roles in biotic and abiotic stress response, but also regulate growth and development. Grapevine (Vitis vinifera) production is largely limited by stressful climate conditions such as cold stress and the role of WRKY genes in the survival of grapevine under these conditions remains unknown.

Results: We identified a total of 59 VWWRKYS from the $V$. vinifera genome, belonging to four subgroups according to conserved WRKY domains and zinc-finger structure. The majority of $V W W R K Y_{s}$ were expressed in more than one tissue among the 7 tissues examined which included young leaves, mature leaves, tendril, stem apex, root, young fruits and ripe fruits. Publicly available microarray data suggested that a subset of VVWRKYS was activated in response to diverse stresses. Quantitative real-time PCR (qRT-PCR) results demonstrated that the expression levels of $36 \mathrm{VvWRKYS}$ are changed following cold exposure. Comparative analysis was performed on data from publicly available microarray experiments, previous global transcriptome analysis studies, and qRT-PCR. We identified 15 VWWRKYs in at least two of these databases which may relate to cold stress. Among them, the transcription of three genes can be induced by exogenous ABA application, suggesting that they can be involved in an ABA-dependent signaling pathway in response to cold stress.
\end{abstract}

Conclusions: We identified 59 V $W W R K Y_{S}$ from the $V$. vinifera genome and 15 of them showed cold stress-induced expression patterns. These genes represented candidate genes for future functional analysis of VWWRKYS involved in the low temperature-related signal pathways in grape.

Keywords: WRKY transcription factor family, Grapevine, Biotic and abiotic stress, Cold stress

\section{Background}

Plants have a variety of defense mechanisms to protect themselves from adverse environmental effects. Families of transcription factors are involved in these processes by functioning to reorganize gene expression patterns. The WRKY family is among them and plays key roles in modulating genes expression during plant defense in response to pathogens $[1,2]$. The WRKY transcription factors were first identified in sweet potato (SPF1) as DNA binding proteins [3]. Two similar genes ( $A B F 1$ and $A B F 2)$

\footnotetext{
*Correspondence: shhli@wbgcas.cn; xinhaiping215@hotmail.com ${ }^{1}$ Key Laboratory of Plant Germplasm Enhancement and Specialty Agriculture, Wuhan Botanical Garden, The Chinese Academy of Sciences, Wuhan, PR China ${ }^{2}$ Beijing Key Laboratory of Grape Sciences and Enology, Laboratory of Plant Resources, Institute of Botany, The Chinese Academy of Sciences, Beijing, PR China

Full list of author information is available at the end of the article
}

were found in wheat during germination [4]. Subsequently, Rushton et al. [5] reported the identification and characterization of WRKY1, WRKY2 and WRKY3 from parsley (Petroselinum crispum) and proposed these genes belong to a gene family. This gene family was named WRKY due to a conserved region (WRKYGQK) that was identified in the $\mathrm{N}$-terminal amino acid sequence of all the members $[4,5]$. Further studies showed that the conserved WRKY domain had other forms such as WRKYGKK and WRKYGEK [6], or the WRKY domain could be replaced by WKKY, WKRY, WSKY, WIKY, WRIC, WRMC, WRRY or WVKY $[7,8]$.

According to variation in WRKY domain and a zinc finger motif in the C-terminus, WRKY proteins were divided into four groups $[9,10]$. WRKY proteins with two WRKY domains composed group I. Groups II and III were characterized by a single WRKY domain. Group II 
WRKY proteins were further subdivided into five or more subgroups based on short conserved structural motifs while group III proteins contained a variant zincfinger which ends with HXC. Finally, group IV WRKY proteins contained the WRKY domain, but lack a complete zinc-finger structure in the C-terminus. WRKY proteins usually functioned as transcriptional regulators via binding to $\mathrm{W}$-boxes (TTGACC/T) in the promoter regions of down-stream genes and clusters of $\mathrm{W}$-boxes had an amplified effect [3-5,11-15]. However, some other studies have found that some WRKY proteins bind to the PRE4 element (TGCGCTT), SURE element (TAAA GATTACTAATAGGAA) or SURE-like element and the WK box (TTTTCCAC) [2].

WRKY proteins have been found to play essential roles in pathogen defense in response to bacteria [16,17], fungi $[18,19]$, and viruses $[20,21]$. Evidence also supported that WRKY transcription factors were involved in modulating gene expression in plants during abiotic stresses such as cold [22,23], salt [24,25] and drought [26-28]. Besides roles in response to biotic and abiotic stress, WRKY proteins were also implicated in processes that modulate plant developmental processes such as morphogenesis of trichomes and embryos, senescence, dormancy, and metabolic pathways [2].

Grape is one of the most important fruit crops worldwide. The productivity of grapevines is largely limited by disease pressure and stressful fluctuations in environmental conditions. Due to their essential role in the early response to pathogens and abiotic stresses, several WRKY genes were intensively studied in grape. VvWRKY1 and $V \nu W R K Y 2$, isolated from grape ( $V$. vinifera $\mathrm{cv}$. Cabernet Sauvignon) berries, were found to potentially participate in defending against fungal pathogens [18,29]. $V \nu W R K Y 1$ was found involving in enhanced protection against Botrytis cinerea by transactivating the VvLTP1 promoter [30], and $V v W R K Y 2$ may regulate lignification and response to biotic or abiotic stresses in grapevine [31]. VpWRKY1 and $V p W R K Y 2$, isolated from Chinese wild $V$. pseudoreticulata, may contribute to resistance to powdery mildew (Erysiphe necator) and tolerance to salt and cold stresses in grape [32]. VpWRKY3 was found to be involved in pathogen defense and also interact with the salicylic acid, ethylene, and abscisic acid signal pathways [33]. Transgenetic Arabidopsis plants expressing VvWRKY11, isolated from 'Beifeng', an interspecific cultivar of $V$. thunbergii $\times$ $V$. vinifera, showed increased dehydration tolerance [34]. Its homologous gene, $V p W R K Y 11$, was found to serve as a negative regulator of disease resistance [35]. Although several individual WRKY genes have been identified in grapevine, the WRKY gene family in grapevine remains wholly uncharacterized.

Based on our previous transriptome analysis, we found that some WRKY genes respond to cold stress in different patterns in $V$. amurensis (a cold hardy grapevine species) and $V$. vinifera cv. Muscat Hamburg [36]. VvWRKY14 (GSVIVT01015952001) and VvWRKY12 (GSVIVT0101 2682001) were found up-regulated over 30 fold in $V$. amurensis after being subjected to cold stress but upregulated to a lesser extent in $V$. vinifera. In contrast, the expression of VvWRKY43 (GSVIVT01030258001) was upregulated in $V$. vinifera (26 fold) while expression remained low in $V$. amurensis. These different gene expression patterns in response to cold stress may be contribute to the distinctive cold hardiness between the two species. To further characterize how WRKY genes respond to freezing stress of grapevine, we initiated this study to identify the entire WRKY gene family in grapevine based on the published $12 \times V$. vinifera $\mathrm{cv}$. Pinot noir (PN40024) genome sequences [37]. A phylogenetic tree was constructed for identified WRKY proteins and the gene expression patterns in different tissues of $V$. vinifera were detected by RT-PCR. WRKY genes responding to biotic and abiotic stresses were cross-evaluated by using public gene-chip databases. Additionally, real time RT-PCR was used to detect the expression level of $V v W R K Y S$ under cold treatment and exogenous ABA. A comparative analysis was conducted to identify $V v W R K Y s$ that may participate in cold signal transduction pathways in $V$. vinifera using microarray data in public databases, our previously reported transcriptome data and qRT-PCR analysis conducted in this study.

\section{Results}

\section{Identifying of WRKY transcription factors in V. vinifera genome}

A total of 64 transcripts in the $V$. vinifera genome sequence were identified as possible members of the WRKY family. Five transcripts were excluded due to a lack of the conserved WRKY domain in the predicted amino acid sequences. The remaining 59 transcripts were named from $V v W R K Y 1$ to $V v W R K Y 59$ according to their order in the $V$. vinifera genomic sequence (Table 1). As for the previously published six WRKY proteins in grapes [18,29-35], each amino acid sequence was downloaded and BLASTp was used to find its corresponding WRKY loci in the $V$. vinifera genome.

The putative genome location of each $V v W R K Y$ in the grape genome was shown in Additional file 1: Figure S1. Fifty-eight of the $V v W R K Y_{\mathrm{S}}$ could be mapped to 18 of the 19 grape chromosomes, with no VvWRKYs found on chromosome 3. VvWRKY4 was putatively located on the 'Chromosome Unknown'. WRKY transcription factors were not evenly distributed across the chromosomes of the grape genome. There were most abundant on Chromosome 4. (8 VvWRKYs) and chromosome 7 (7 $V \nu W R K Y s)$ and least abundance on Chromosome 5 and 18 (1 VvWRKY). 
Table 1 Identified WRKY genes in 12× V. vinifera 'Pinot Noir' genome

\begin{tabular}{|c|c|c|c|c|c|}
\hline Gene ID & Gene symbol & Subgroup & Chromosome no. & Peptide length & Related publications \\
\hline GSVIVT01000752001 & VWWRKYO1 & IId & chr7 & 285 & \\
\hline GSVIVT01001286001 & VWWRKYO2 & IV & chr2 & 106 & \\
\hline GSVIVT01001332001 & VVWRKYO3 & । & chr1_random & 436 & VVWRKY2 $[29,30]$ \\
\hline GSVIVT01007006001 & VVWRKYO4 & I & chrun & 551 & \\
\hline GSVIVT01008046001 & VVWRKY05 & $\| \mathrm{b}$ & chr17 & 606 & \\
\hline GSVIVT01008553001 & VVWRKYO6 & Ilc & chr17 & 152 & VVWRKY1 [18] \\
\hline GSVIVT01009441001 & VWWRKYOT & $\| d$ & chr18 & 320 & \\
\hline GSVIVT01010525001 & VVWRKY08 & \|c & chr1 & 190 & \\
\hline GSVIVT01011356001 & VVWRKYO9 & $\| \mathrm{b}$ & chr14 & 503 & \\
\hline GSVIVT01011472001 & VVWRKY10 & I & chr14 & 890 & \\
\hline GSVIVT01012196001 & VVWRKY11 & $\| c$ & chr1 & 284 & \\
\hline GSVIVT01012682001 & VVWRKY12 & $\| \mathrm{b}$ & chr10 & 511 & \\
\hline GSVIVT01014854001 & VVWRKY13 & । & chr19 & 623 & \\
\hline GSVIVT01015952001 & VWWRKY14 & $\| a$ & chr9 & 279 & \\
\hline GSVIVT01018300001 & VVWRKY15 & Ilc & chr15 & 229 & \\
\hline GSVIVT01019109001 & VVWRKY16 & I & chr4 & 487 & \\
\hline GSVIVT01019419001 & VVWRKY17 & lle & chr2 & 324 & \\
\hline GSVIVT01019511001 & VWWRKY18 & III & chr2 & 343 & \\
\hline GSVIVT01020060001 & VWWRKY19 & $\| \mathrm{b}$ & chr1 & 595 & \\
\hline GSVIVT01020864001 & VVWRKY2O & $\| c$ & chr12 & 312 & \\
\hline GSVIVT01021252001 & VVWRKY21 & He & chr10 & 279 & \\
\hline GSVIVT01021397001 & VWWRKY22 & $\| c$ & chr10 & 320 & \\
\hline GSVIVT01021765001 & VWWRKY23 & Ile & chr10 & 422 & \\
\hline GSVIVT01022067001 & VVWRKY24 & $\| d$ & chr7 & 281 & \\
\hline GSVIVT01022245001 & VVWRKY25 & $\| c$ & chr7 & 194 & \\
\hline GSVIVT01022259001 & VWWRKY26 & Ilc & chr7 & 227 & \\
\hline GSVIVT01023600001 & VVWRKY27 & । & chr11 & 500 & VpWRKY2 [30] \\
\hline GSVIVT01024624001 & VVWRKY28 & । & chr6 & 571 & \\
\hline GSVIVT01025491001 & VVWRKY29 & IV & chr6 & 122 & \\
\hline GSVIVT01025562001 & VVWRKY30 & । & chr8 & 439 & \\
\hline GSVIVT01026965001 & VVWRKY31 & lle & chr15 & 349 & \\
\hline GSVIVT01026969001 & VVWRKY32 & Ilc & chr15 & 202 & \\
\hline GSVIVT01027069001 & VVWRKY33 & III & chr15 & 361 & \\
\hline GSVIVT01028129001 & VVWRKY34 & He & chr7 & 243 & \\
\hline GSVIVT01028147001 & VVWRKY35 & $\| c$ & chr7 & 303 & \\
\hline GSVIVT01028244001 & VWWRKY36 & $\| b$ & chr7 & 480 & \\
\hline GSVIVT01028718001 & VWWRKY37 & III & chr16 & 365 & \\
\hline GSVIVT01028823001 & VVWRKY38 & \|le & chr16 & 183 & \\
\hline GSVIVT01029265001 & VWWRKY39 & $\| d$ & chr11 & 280 & \\
\hline GSVIVT01029688001 & VVWRKY4O & $\| b$ & chr12 & 491 & \\
\hline GSVIVT01030046001 & VVWRKY41 & । & chr12 & 365 & \\
\hline GSVIVT01030174001 & VVWRKY42 & III & chr8 & 332 & VpWRKY1 [30] \\
\hline GSVIVT01030258001 & VVWRKY43 & । & chr8 & 514 & \\
\hline GSVIVT01030453001 & VVWRKY44 & $\| \mathrm{b}$ & chr12 & 499 & \\
\hline
\end{tabular}


Table 1 Identified WRKY genes in $12 \times$ V. vinifera 'Pinot Noir' genome (Continued)

\begin{tabular}{|c|c|c|c|c|c|}
\hline GSVIVT01032661001 & VVWRKY45 & III & chr13 & 289 & \\
\hline GSVIVT01032662001 & VVWRKY46 & III & chr13 & 309 & \\
\hline GSVIVT01033063001 & VVWRKY47 & Ilc & chr14 & 183 & \\
\hline GSVIVT01033188001 & VVWRKY48 & Ild & chr4 & 268 & WRKY11 [33,34] \\
\hline GSVIVT01033194001 & VWWRKY49 & \|c & chr4 & 157 & \\
\hline GSVIVT01033195001 & VWWRKY50 & Ilc & chr4 & 102 & \\
\hline GSVIVT01034148001 & VVWRKY51 & Ilc & chr8 & 300 & \\
\hline GSVIVT01034968001 & VVWRKY52 & Ilc & chr5 & 310 & \\
\hline GSVIVT01035426001 & VVWRKY53 & Ilc & chr4 & 167 & \\
\hline GSVIVT01035884001 & VVWRKY54 & Ila & chr4 & 263 & \\
\hline GSVIVT01035885001 & VVWRKY55 & Ila & chr4 & 287 & VpWRKY3 [32] \\
\hline GSVIVT01035965001 & VVWRKY56 & । & chr4 & 531 & \\
\hline GSVIVT01036223001 & VVWRKY57 & Ild & chr14 & 305 & \\
\hline GSVIVT01037686001 & VVWRKY58 & $\| \mathrm{lb}$ & chr19 & 497 & \\
\hline GSVIVT01037775001 & VVWRKY59 & I & chr19 & 553 & \\
\hline
\end{tabular}

\section{Categorization of VvWRKYs basis on conserved WRKY domains}

The disposition of structural domains in amino acid sequences is an important clue to analyze the evolution and relationship between highly divergent sequences [38]. The relationships among the 59 WRKY proteins were investigated through constructing phylogenetic trees based on multiple alignments of the predicted amino acid sequences of the WRKY domains. As shown in Figure 1, we classified the 59 VvWRKY proteins into four large groups according to the results of the phylogenetic analyses. The models of conserved amino acid sequences of WRKY domain and zinc-finger structure in four groups were shown in Additional file 2: Figure S2. Twelve of the WRKY proteins contained two complete WRKY domains and a $\mathrm{C}_{2} \mathrm{H}_{2}$-type zinc finger motif. These proteins constituted group I. The N-terminal WRKY domain (NTWD) and C-terminal WRKY domain (CTWD) of VvWRKY27, VvWRKY41 and VvWRKY56 were clustered into a same clade in group I. According to Eulgem et al. [9] and by using WRKY proteins in Arabidopsis as references, $39 \mathrm{VvWRKY}$ in group II were categorized into five subgroups. Three members were found in subgroup IIa, 8 in IIb, 16 in IIc, 6 in IId and 6 in IIe. Group II was divided into two parts. Subgroup IIa, IIb and IIc showed a close relationship with Group III WRKY proteins. And subgroups IId and IIe belonged to a separate clade which was closely related to group IV. Subgroup IIc showed higher divergence than the other subgroups. There were also $6 \mathrm{WRKY}$ proteins in group III, and 2 in group IV which lacked a complete zinc-finger structure.

\section{RT-PCR based transcription levels detection of VvWRKYs} in different tissues

To investigate if the putative $V v W R K Y s$ were expressed and assess their transcription levels in grape, we examined the expression of these genes in different grape tissues. Among all VvWRKYs, we successfully designed and verified 58 primer pairs representing all candidate $V \nu W R K Y_{\mathrm{S}}$ except for VvWRKY38 (Figure 2). All transcripts can be detected at least in one tissue. Nineteen VvWRKYS (including VvWRKY02, 11, 12, 13, 14, 17, 20, $24,28,30,33,34,35,36,39,41,42,48$ and 52) were found expressed in all tissues used. Six $V v W R K Y s$ (VvWRKY05, 09, 22, 40, 44 and 58) were found only expressed in young tissues. VvWRKY05 was expressed in the stem apex and young fruit. VvWRKY40 was found in stem apex, young fruit and root. VvWRKY09, 22, 44 and 58 were detected in young leaf, stem apex, young fruit and root.

\section{Gene-chip based expression analysis of $26 \mathrm{VvWRKYs}$ under various stresses}

Although we identified WRKY transcription factors from the $V$. vinifera genome, functions for these genes in response to abiotic and biotic stress remain unknown. Using microarray results from publically available data, it was possible to find gene expression data from multiple experimental conditions for several of the grapevine WRKY genes. We carefully checked the genes on the 'GeneChip Vitis vinifera (Grape) Genome Array' (Affymetrix) and a total of $26 V v W R K Y_{\mathrm{S}}$ were found on this chip. Microarray data related to salinity, water-deficit, PEG, cold, ABA and pathogen stresses were downloaded 


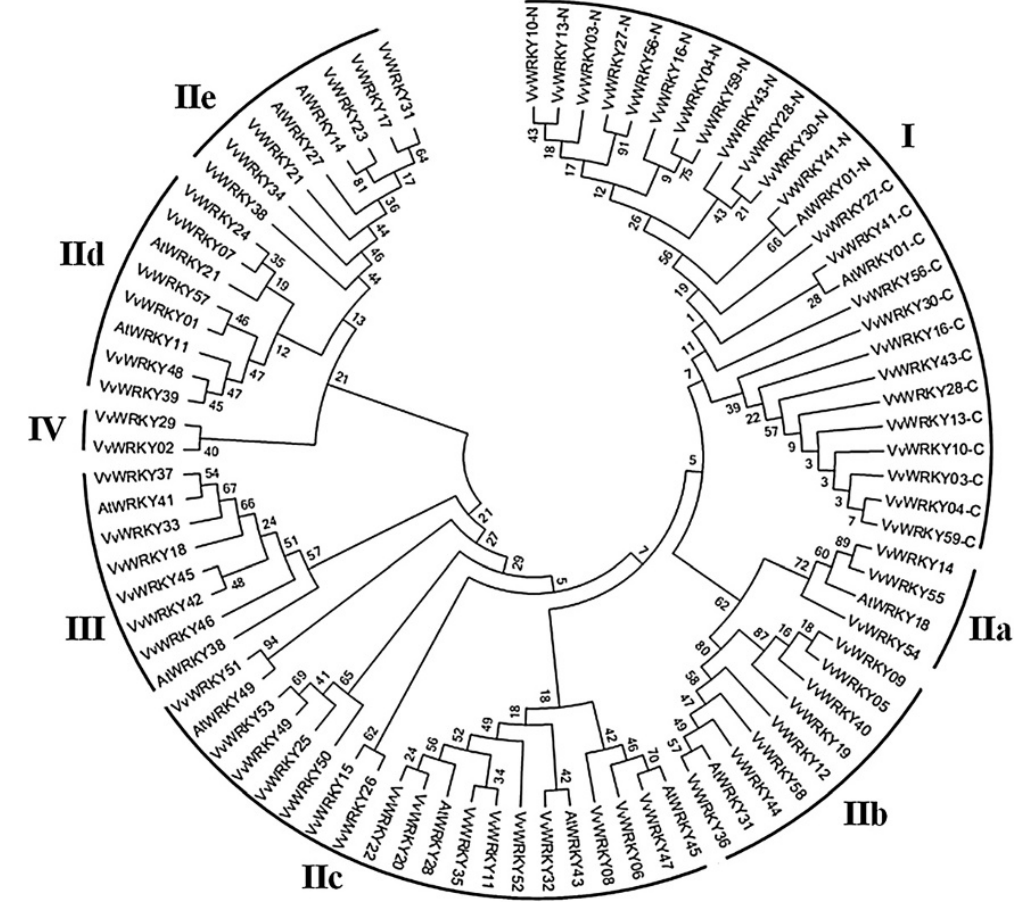

Figure 1 Phylogenetic tree of VvWRKYs. The unrooted phylogenetic tree of WRKY domains was constructed with MEGA5.1 program with the neighbor-joining method. The numbers beside the branches represent bootstrap values based on 1000 replications. The name of groups (I, II, III and IV) and subgroup (a-e) were shown at the outside of the circle. The WRKY named with suffix - $\mathrm{N}$ or -C indicated the N-terminal WRKY domain (NTWD) or the C-terminal WRKY domain (CTWD) in one VVWRKY with two WRKY domains. AtWRKYs were used as reference to categorize VVWRKYs.

and their corresponding probes and the $\mathrm{CV}$ (coefficent of variation of the corresponding treatment means) of these genes in each of the microarray experiments were listed in Additional file 3: Table S1. If the expression of a probe set (gene) is affected by some of the treatments in an experiment, it shows a higher CV (more fluctuation); and vice versa. According to the data, the $\mathrm{CV}$ of 20 of the $26 V v W R K Y s$ were over $5 \%$ in at least one experiment. The highest CV appeared in VvWRKY57 (up to $36 \%$ ) associated with compatible viral diseases in berry experiment in $V$. vinifera cv. Cabernet Sauvignon. VvWRKY03, 06, 08, 28, and 55 responded to both abiotic and pathogens stresses while VvWRKY21, 39, 48 seemed to respond primarily to pathogens stresses.

To test the correlation between the expression patterns of $26 V v W R K Y \mathrm{~s}$ and their phylogenetic relationship, a hierarchical cluster analysis was performed using the 11 stress related experimental datasets (Figure 3). Red, black and green elements in the matrix indicate up-, no change- and down-regulated expression of WRKY transcription factors, respectively. From the heat map, twenty-six genes were clustered into four clades. Carefully analyzing the cluster of expression data in response to abiotic stresses experiments and comparing this with the VvWRKYs phylogenetic tree, we found that genes with close phylogenetic relationship were classified into the same clade during hierarchical cluster analysis. The most obvious evidence can be found in clades 3 with 5 WRKY subgroup IId genes (including VvWRKY07, 24, 39, 48 and 57), which show similar expression patterns in response to salt, PEG and cold stresses. Clade 1 contained three WRKY group I genes and two group IIC genes. Clade 2 was mainly composed by WRKY group I and IIC and contains a majority of cold stress-related $V v W R K Y s$ (Also shown in Additional file 4: Table S2). Clade 4 only had one gene and that gene was from WRKY group III.

\section{Real-time RT-PCR based expression analysis of $V v W R K Y s$ under cold treatment in $V$. vinifera}

To examine the response of $V v W R K Y$ s under cold stress in grape, we examined the transcription levels of $V v W R K Y \mathrm{~s}$ in shoot apices of 'Muscat Hamburg' under cold-treatment $\left(4^{\circ} \mathrm{C}\right) . V v$ WRKYO5, 21, 32 and 40 were excluded from cold-treated experiment since their $\mathrm{Ct}$ value of amplification curve were over 35 cycles in the templates of normal and cold-treated shoot apex. Detected $V v W R K Y s$ can be classified into four groups according to expression patterns as shown in Figure 4 and Additional file 5: Figure S3: A) sustained up-regulated during cold treatment (22 genes, Figure 4A), B) changed above 2 fold with irregular pattern (9 genes, Figure 4B), 


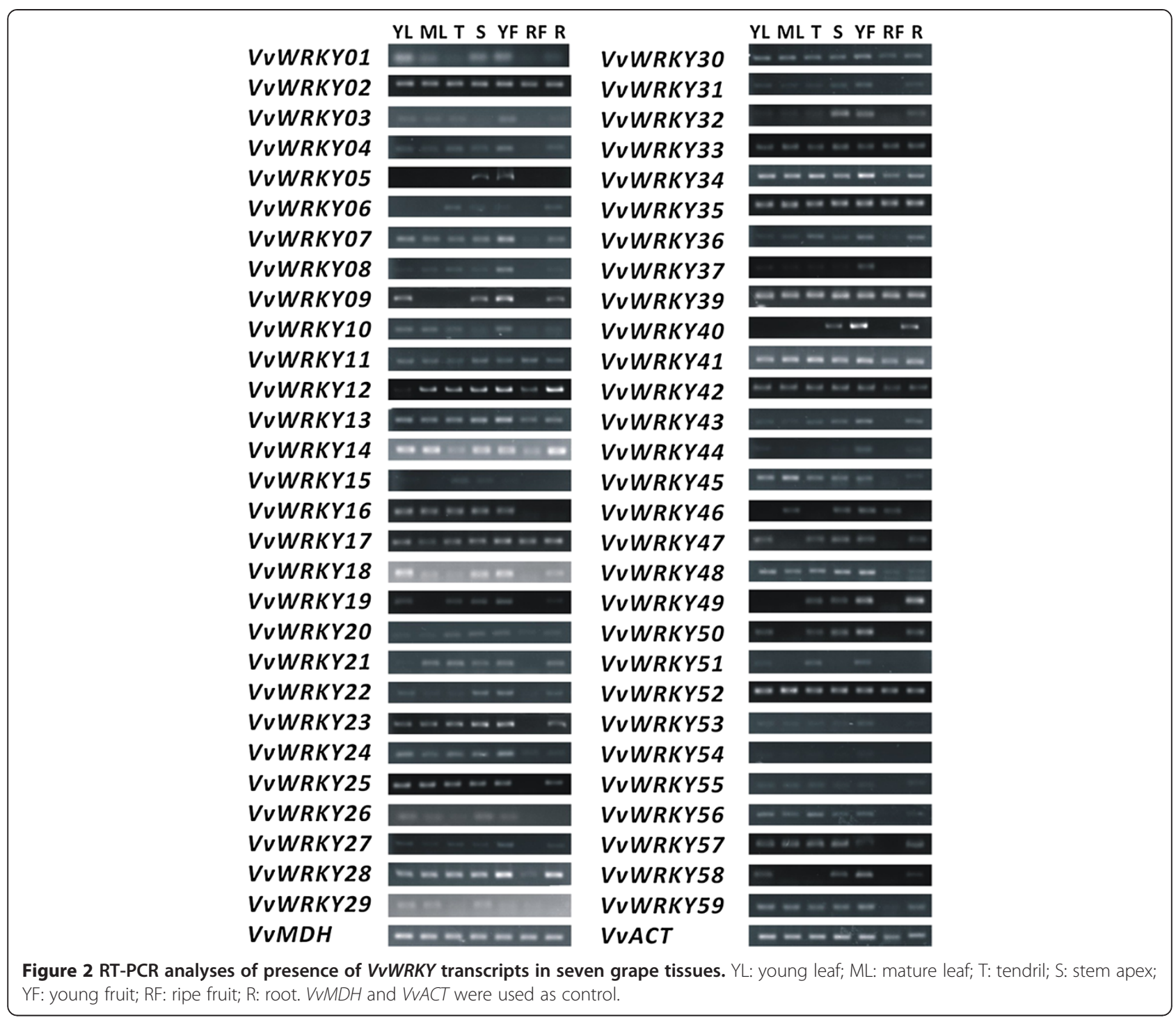

C) sustained down-regulated (5 genes, Figure 4C) and D) no significant difference (18 genes, as shown in Additional file 5: Figure S3). The relative expressions of 36 genes (Figure 4A, B and C) were significantly different as cold treatment. The greatest increase in expression (nearly 30 fold) was found in VvWRKY55 at $48 \mathrm{~h}$ cold treatment. $V \nu W R K Y 18$ and $V \nu W R K Y 46$ had the largest up-regulation of greater than 6 fold at 8 hours after cold treatment. While VvWRKY18 was degraded after 24 hours, the expression of VvWRKY46 demonstrated both up and down regulated with a spike of expression at 48 hours after intensive degradation at 24 hours.

Exogenous ABA induced accumulation of $V v W R K Y s$ in V. Vinifera

To illustrate how the $V \nu W R K Y s$ respond to ABA and whether the cold stress related $V v W R K Y S$ may participate in the ABA-dependent cold signal pathway, ABA treated grapevine apices were examined using qRT-PCR. $V \nu W R K Y 12,29$, and 46 were excluded from this experiment due to their higher $\mathrm{Ct}$ value (Figure 4D and Additional file 6: Figure S4). Among the $55 \mathrm{VvWRKYS}$ we detected, twelve $V v W R K Y S$ were expressed over 2fold greater within $2 \mathrm{~h}$ of exogenous ABA treatment (Figure 4D). After statistical analyses of qRT-PCR results, 7 of them were evaluated to significantly change during exogenous ABA treatments. Transcripts of $V \nu W R K Y 35$ showed the greatest increase in expression at $0.5 \mathrm{~h}$ after ABA treatments. Six other genes showed increases in expression $1 \mathrm{~h}$ after exogenous ABA treatment (Figure 4D).

When the data from the cold and ABA experiments were compared, 6 of 7 genes (VvWRKY, 19, 28, 35, 42, 50 and 55) that were up-regulated during exogenous ABA treatment were also up-regulated under cold treatment (Figure 4A and B, marked by underline). Two 


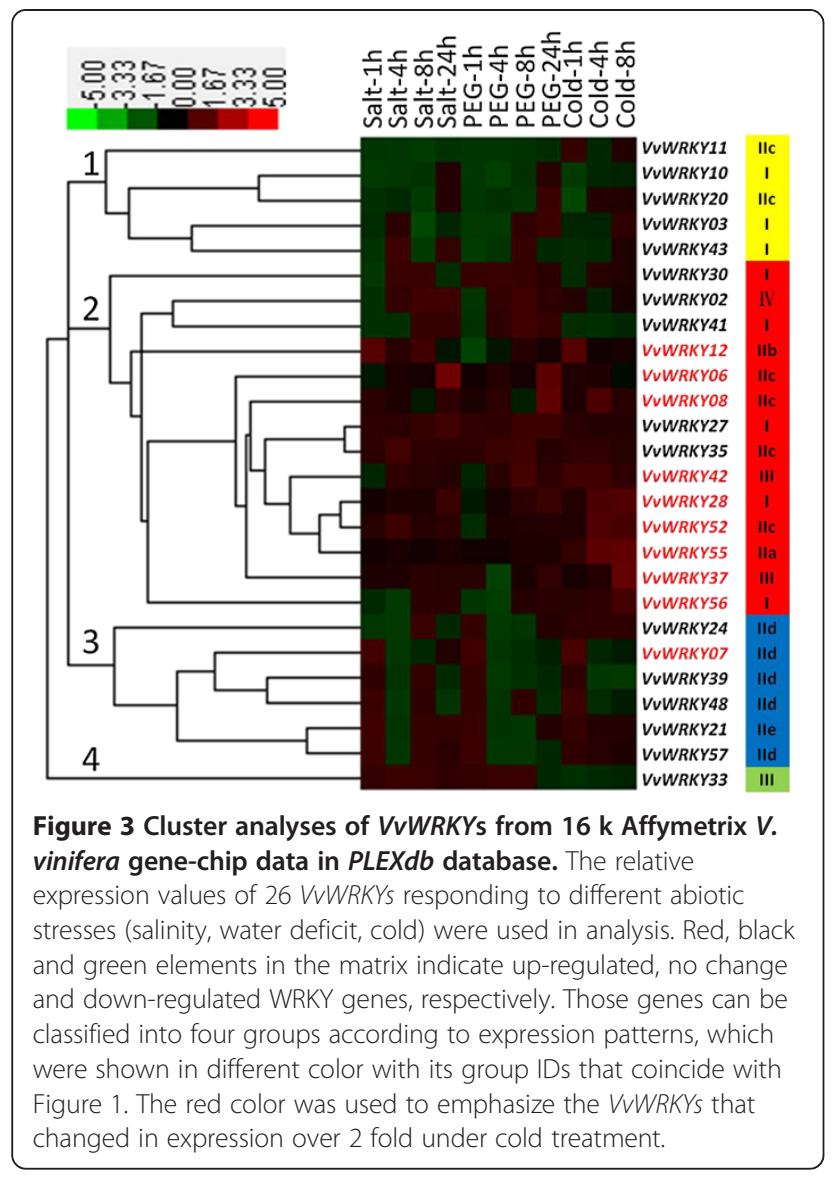

genes $(V \nu W R K Y 55,28)$ were greatly up-regulated, over 10 fold. The expression levels of the rest of the 44 $V v W R K Y S$ were lower than 2-fold and not significantly changed during exogenous ABA treatments (Additional file 6: Figure S4).

\section{Identification of candidate cold-stress related VvWRKYs}

Previously we reported the changes of the transcriptome during cold-treatments in 'Muscat Hamburg' and identified 14 cold-stress related $V v W R K Y s$ (we reported 16 $V v W R K Y s$ but subsequent annotation of these genes allowed us to exclude two genes that do not belong to the WRKY gene family)[36]. Gene-chip based methods also allowed to identify 10 cold-stress related $V v W R K Y s$ [39]. In order to overcome the deficiencies of determining gene expression from a single technological approach and obtain more reliable results, we compared the data from three different methods. Fourteen VvWRKYs from our previous transcriptome analysis, ten from publically available gene-chip based data and 36 genes from qRTPCR results (this study) were used. The results were summarized in Figure 5 and Additional file 4: Table S2. Three VvWRKYs (VvWRKY12, 28, 55) showed identical expression patterns and were found up-regulated over 10 fold in at least one time-point under cold-treatment by qRT-PCR
(Figure 4A). A total of $12 V v W R K Y s$ were confirmed by two experimental methods (Figure 5A and B). VvWRKY56 was identified as up-regulated gene under cold treatment only in the gene-chip studies. Twenty-two genes that were characterized by qRT-PCR were not supported by the other studies. It is worth mentioning that down-regulated $V v W R K Y s$ under cold-treatment were only identified by qRT-PCR based method.

\section{Discussion}

\section{WRKY family in grape}

Considering the important roles that WRKY transcription factors play during plant development and in response to various stresses, it is not surprising that we identified so many family members in grapevine. Previously, 74 WRKY genes were found in Arabidopsis [2], 55 in cucumber [40], 102 in rice [2], 47 in castor bean [41], 86 in Brachypodium distachyon [42] and 136 in maize [43]. Here we identified 59 candidate WRKY proteins in $V$. vinifera and categorized them into four groups.

\section{Group I WRKY proteins}

When compared with WRKY family groups, WRKYs in primitive plant ancestors Giatdia lamblia, Dictyostelium discoideum and Chlamydomonas reinhardtii closely resembled Vitis group I $[7,38]$. In our study, two domains of VvWRKYs in group 1 were closely related. A BLASTp search of EuGene.1100010359 from an ancient alga species (Ostreococcus sp. RCC809) which has a single WRKY domain allowed us to identify 9 corresponding WRKY homologs in grape and 8 of these belonged to group I by MAP VIEW (Plant Genome Duplication Database) [44]. These data support the hypothesis that the dual WRKY domains present in members of group I may be derived from a single WRKY domain duplication [6,7].

\section{Group II WRKY proteins}

Group II was divided into three parts: subgroup IIa + IIb, subgroup IIc and subgroup IId + IIe (Figure 1). Subgroup IIa + IIb belong to the same clade and is sister to the WRKYs in group I. Interestingly, the presumed function of CTWDs in group I for sequence-specific DNA binding [9] were more similar to the single WRKY domain members in group II and III than to the NTWDs of group I, This result may indicate that subgroup IIa + IIb evolved from group I by domain structure loss of the group I NTWD.

\section{Group III WRKY proteins}

Group III in the phylogenetic tree was most closely related to the very large subgroup IIc, which was separately into four clades and seemed to indicate an expansion of the gene family. A thorough search of the Plant Transcription Factor Database (http://planttfdb.cbi.pku.edu.cn) indicated that the earliest evolutionary occurrences of group III 


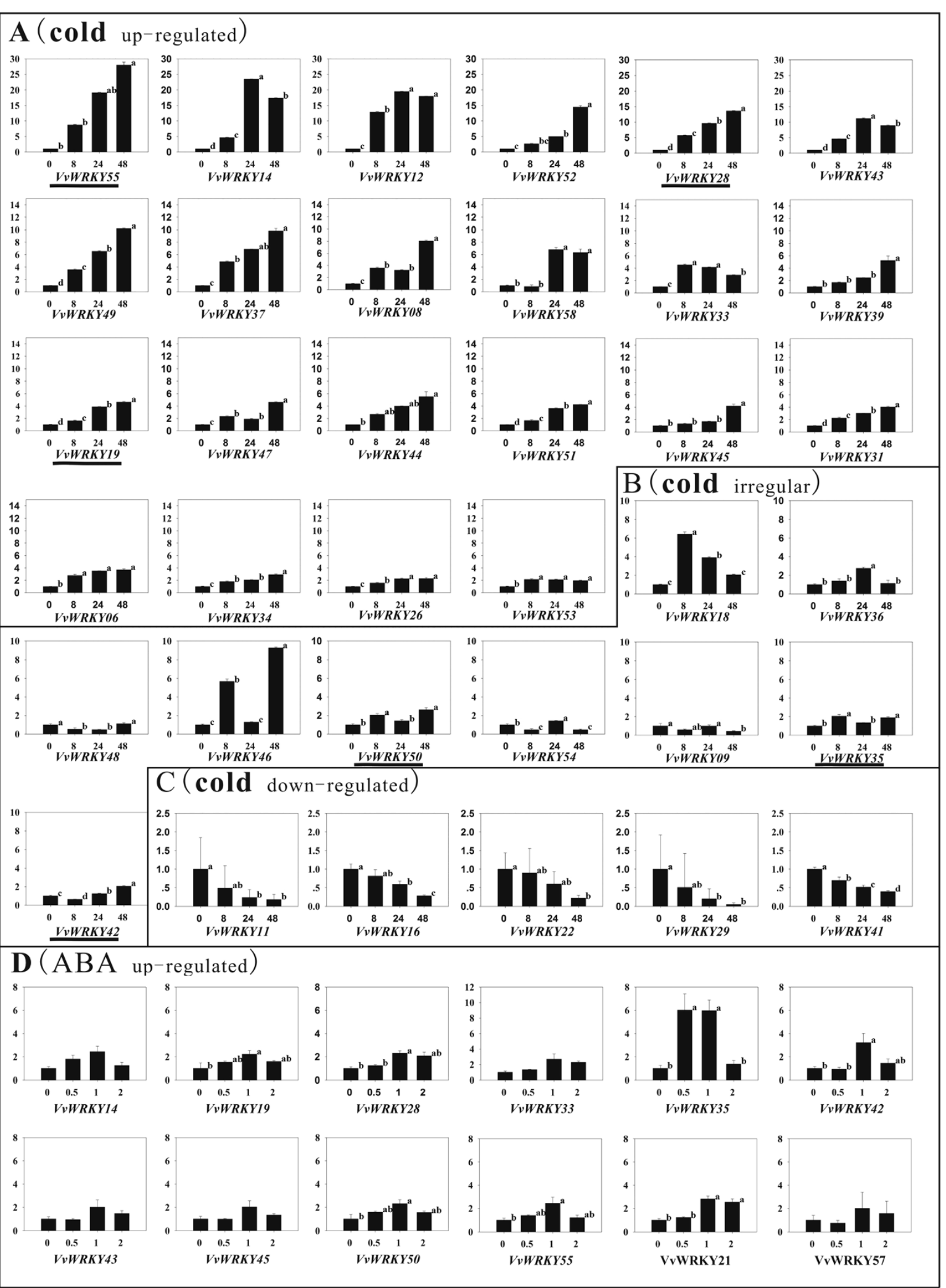

Figure 4 (See legend on next page.) 
(See figure on previous page.)

Figure 4 qRT-PCR assays of the expression patterns of $V v W R K Y s$ under cold and exogenous ABA treatments. The default expression value for each gene was 1 at 0 hours before treatment. $A, B$ and $C$ represent the subgroups with different expression patterns in cold treatment and $\mathrm{D}$ represents the genes that up-regulated over 2 fold in ABA treatment. $\mathbf{A}$ : sustained up-regulated genes in cold treatment; $\mathbf{B}$ : genes that changes over 2 fold but without significant tendency in cold treatment; $\mathbf{C}$ : sustained down-regulated genes in cold treatment; $\mathbf{D}$ : up-regulated genes in exogenous ABA treatment. VWWRKYs that accumulated in both cold and exogenous ABA treatments were underlined. One-Way ANOVA analysis was used to test the impact of timing of cold treatment. When the effects were significantly different, we examined the difference between treatments using post hoc multiple comparisons (LSD, $p<0.05$ ). All data analyses were conducted using IBM SPSS Statistics 20, and the results were displayed through $\mathrm{a}, \mathrm{b}, \mathrm{c}$ and $\mathrm{d}$.

genes were those found in ferns (Selaginella moellendorffii). There was no evidence of any sequenced plant species that only contain members of group I and III but we found in some species with only members of group I and II, for example in mosses (Physcomitrella patens) [1], and some gymnosperms (Pinus taeda) (http://planttfdb.cbi. pku.edu.cn). We speculated that group III may have evolved from group II, particularly IIc. As group III WRKYs in Arabidopsis responded to diverse biotic stresses [45], group III members may indicate adaptation of early plants to the stressful conditons associated with the colonization of land and subsequent increase in biotic pathogen pressures.

\section{Group IV WRKY proteins}

We found that group IV WRKY proteins, which were characterized by the loss of the zinc-finger domain, were in the same clade as subgroups IId + IIe. VvWRKY02 and $V v W R K Y 57$ were duplicated gene pairs according to a whole genome analysis of grapevine gene duplications [46]. This might suggest an origin of group IV from subgroups IId + IIe. Group IV proteins were considered non-functional due to the loss of the zinc-finger domain [10]. However, these genes of group IV can be found in all higher plant species as well as in algaes (Bathycoccus prasinos: Bathy17g02050). Furthermore, some genes were expressed in rice (OsWRKY56) [10] as were two genes identified in this study ( $V v W R K Y 02$ and $V v W R K Y 29)$. Therefore, it remains questionable whether group IV WRKYs have biological function in plants.

\section{VvWRKYs participate in development and stress-related signal pathways}

WRKY genes were found to be expressed in many tissues and seem to be involved in regulating plant developmental and physiological processes. Transcriptomic analysis of senescence in the flag leaf of wheat demonstrated that WRKY transcription factors are greatly up-regulated during the senescence process [47]. OsWRKY78 was found to be up-regulated in elongating stems and knockdown mutations in this gene cause plants to produce a semidwarf and small seed phenotype caused by reducing cell length [48]. Moreover, the transcription of GhWRKY15 was observed abundant in the roots and stems of tobacco and transgenic overexpression lines of these plants displayed faster elongation at the earlier shooting stages [49]. Here the expression of $15 \mathrm{VvWRKYs}$ (Figure 2) can be detected in all grape tissues we used, which may indicate its fundamental roles in different cell-types in grape. Similar to expression patterns observed in other plant species,

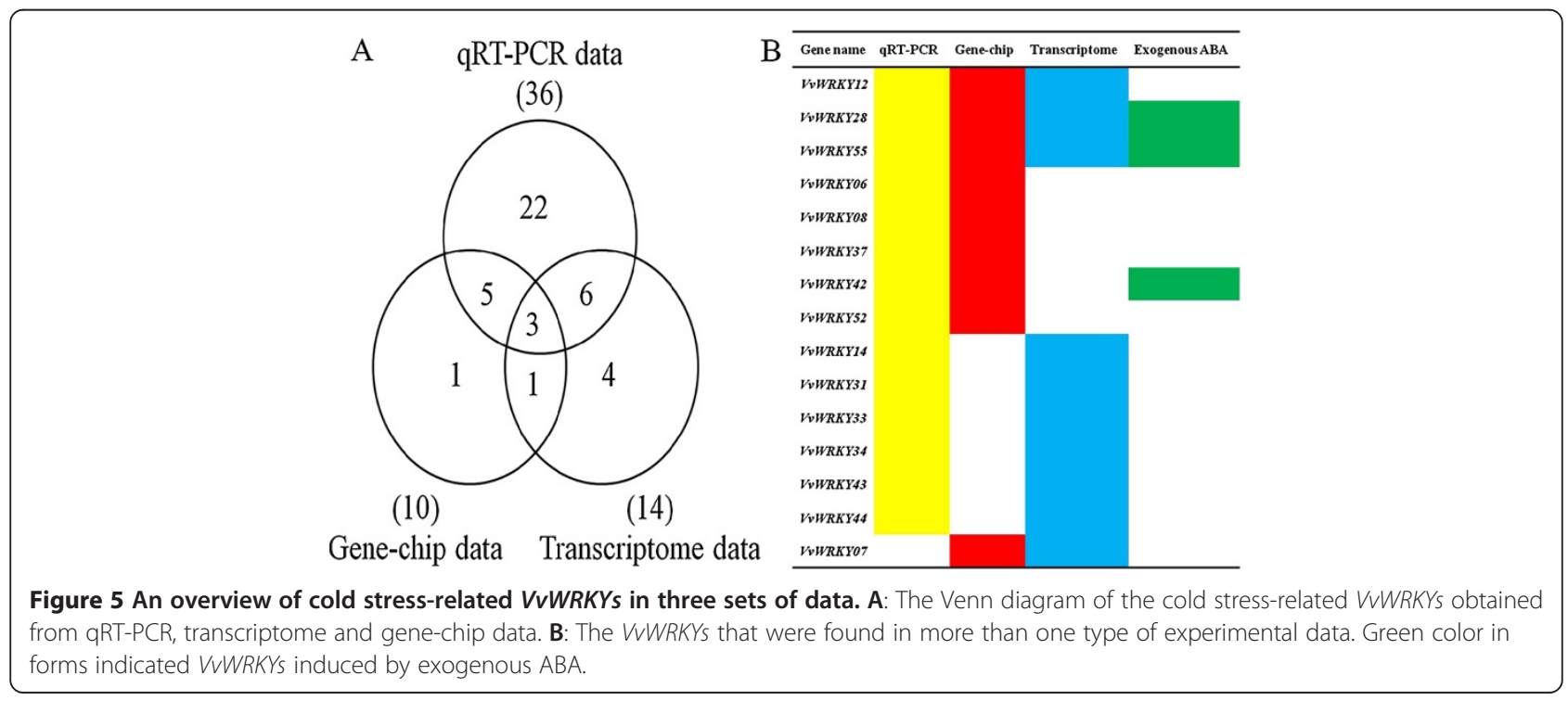


$V \nu W R K Y s$ were found to be expressed in young tissues such as young leaf, shoot apex, tendril and young fruit.

Several numbers of VvWRKYs were found activated in more than one type of stress condition (Figure 3 and also Additional file 3: Table S1). VpWRKY3, homologous to VvWRKY55 was observed to be up-regulated in response to many different sources of stress, including pathogen exposure, salicylic acid, ethylene, cold and drought stress [32]. VvWRKYs that were up-regulated in response to more than two types of stresses (e.g. pathogen and drought) supported the occurrence of cross-talk between signal transduction pathways in response to different stress conditions in plants [50].

Phylogenetic relationships between $V \nu W R K Y$ genes suggested that there may be conserved responses of these genes to salt exposure, PEG and cold-stress (Figure 3). All members of group IId clustered into one clade with similar expression pattern during these three stress conditions, suggesting the function of these VvWRKY proteins may relate to the structures of WRKY domains. Subgroup IId was identified as a novel CaM-binding transcription factor family in plants and their conserved structural motif was a $\mathrm{Ca}^{2+}$-dependent CaM-binding domain [51]. Thus the placement of the WRKYs in the phylogenetic tree may also help to predict function of new members that belong to certain gene family.

\section{VvWRKYs that participate in the cold related signal transduction in grape}

Three different experimental methods were combined to robustly analyze the response of VvWRKY genes to cold stress (Figure 5 and Additional file 4: Table S2). Results from qRT-PCR demonstrated the greatest number of cold stress-related VvWRKYs (36) while gene-chip based methods identified the least, $10 \mathrm{~V} v W R K Y s$. This difference may be attributed to the method used but is also likely due to differences in the treatment conditions between experiments. During Digital Gene Expression profile (DGE) analysis [36], plant material was obtained from $4 \mathrm{~h}$ cold treatment at $4^{\circ} \mathrm{C}$, whereas in our pRTPCR experiment, we used samples collected at several different time periods (at $8 \mathrm{~h}, 24 \mathrm{~h}$ and $48 \mathrm{~h}$ after cold treatment at $4^{\circ} \mathrm{C}$ ). Additionally, multiple matched tags were excluded from the final analysis performed by Xin et al. [36], which may have reduced the number of identified cold related $V v W R K Y$ s. Finally, gene-chip based methods may bias results due to a lower number of genes with corresponding probes related to the WRKY proteins (only 26 WRKY). By integrating the data from different methods, we obtained more reliable results and a total of 15 candidate cold tolerance VvWRKYS (Figure 5) were identified during our investigation.

According to previous studies, the transcriptional control of plant responses to cold stress can be divided into
ABA-dependent and ABA-independent signal pathways [52]. The results of our study also indicated that $15 \mathrm{pu}-$ tative cold stress-related $V \nu W R K Y s$ can be divided into two groups according to their responses to exogenous ABA. Three $V v W R K Y s$ ( $V v W R K Y 28,42$ and 55) may participate in an ABA-dependent signal pathway and other 12 in ABA-independent pathway. WRKY transcription factors have been identified as key components in the ABA signaling pathways [8,53]. In rice, OsWRKY24, 51, 71 and 72 are induced by (ABA) in aleurone cells. OsWRKY24 and 45 were functional as negative regulators in ABA induction of the HVA22 promoter-betaglucuronidase construct, while OsWRKY72 and 77 synergistically interacted with $\mathrm{ABA}$ to activate this reporter construct [10]. It is still unknown how WRKYs participate in the cold stress-related signal pathway and what relationship these genes have with C-repeat Binding Factor genes (CBFs), which are critical transcription factors responsible for cold tolerance in plant [54].

The reliability of the identified 15 cold-related $V \nu W R K Y s$ was also supported by homologous genes in other species. STHP-64, which showed high similarity with VvWRKY43, was not present in leaves until November and December in Solanum dulcamara [55]. WRKY38, a homolog gene of $V v W R K Y 14$, was transiently accumulated when leaves and roots were exposure to low temperature in barley [56]. BcWRKY46 showed higher similarity with $V v W R K Y 33$ and responded to low temperatures in Pak-choi. Constitutive expression of BcWRKY46 reduced the freezing susceptibility in transgenic tobacco [57]. The transcription level of VvWRKY55 was upregulated robust under cold treatment. Its homolog gene, WRKY71 was found in banana with a similar expression pattern [58]. All these $V v W R K Y s$ mentioned above were confirmed by at least two set of experiment methods, which provided appropriate candidates to illustrate the roles of WRKY protein under low temperature-related signal pathways in grape.

Although low-temperature related WRKYs were isolated in several species, the mechanism of how WRKYs respond to cold signals and regulate the expression of downstream genes is still largely unknown. Further work is needed to elucidate the function of these important genes in low-temperature related signal pathways. Previously we reported the different expression patterns of WRKYS in $V$. amurensis, a cold-hardness species. The WRKY genes identified here from $V$. vinifera may accelerate the functional analysis of this gene family in $V$. amurensis. The comprehensive analysis of cold stressrelated WRKYS in two different Vitis species with contrasting cold hardiness phenotypes would certainly help to illustrate the function of WRKY genes in conveying cold hardiness in grapevine. 


\section{Conclusions}

In summary, a total of $59 \mathrm{VvWRKYS}$ in the $V$. vinifera genome were identified. The $V v W R K Y s$ were unevenly distributed in 18 of the 19 chromosomes. WRKY domain based phylogenetic analysis allowed categorizing $59 \mathrm{VvWRKYs}$ into four large groups. A majority of $V v W R K Y s$ were found expressed in more than one tissue in $V$. vinifera. Gene-chip based data analysis suggested that a subset of $V v W R K Y s$ was activated in respond to diverse biotic and abiotic stresses. The transcription level of $36 V v W R K Y$ genes changed over 2 fold after cold induction. A comparative analysis of qRT-PCR results, gene-chip based data and transcriptome analysis allowed us to identify $15 V v W R K Y s$ that show identical expression patterns during cold treatment at least in two kinds of analyses. These studies not only increase our knowledge of WRKY family, but also provide candidate genes for future functional analysis of $V v W R K Y s$ involved in the low temperature-related signal pathways in grape.

\section{Methods}

Identification of WRKY genes in the grape genome

Candidate WRKY proteins were identified from the $12 \mathrm{X}$ $V$. vinifera cv. Pinot noir genome (quasi-homozygous line PN40024, http://www.phytozome.net). Full-length amino acids sequences of all WRKY proteins in Arabidopsis thaliana (http://www.arabidopsis.org/) were used as query sequences. A BLASTp search was performed and $E$-value of $\mathrm{e}^{-6}$ was used as the threshold [59]. Candidate WRKY proteins were manually confirmed [60] by searching for WRKY domains in the candidate amino acids sequences using SWISS-MODEL (http://swissmodel.expasy.org/) and the results were shown in Table 1.

\section{Phylogenetic analysis of WRKY family}

Multiple alignments of the amino acid sequences of 73 WRKY domains from $V$. vinifera were performed using CLUSTALW by MEGA5.1 [61]. Twelve Arabidopsis WRKY domains from different WRKY groups were used as references to categorize the WRKY proteins from grape. The GenBank accession numbers of those AtWRKYs are AtWRKY01: ABJ17102, AtWRKY11: AEE85928.1, AtWRKY14: AAP21276.1, AtWRKY18: AAM78067, AtWRKY21: AAB63078.1, AtWRKY27: ABH04558, AtWRKY28: AEE84006, AtWRKY31: AEE84546.1, AtWRKY38: AED93044.1, AtWRKY41: AEE82969, AtWRKY43: AEC10646.1, AtWRKY45: ABD57509.1, AtWRKY49: AAQ62425.1. The parameters used during alignment were: protein weight matrix: Gonnet series; negative matrix: on; gap open penalty: 10; gap extension penalty: 0.20 ; delay divergent sequences: 30 ; residuespecific gap penalties: on; hydrophilic penalties: on; gap separation distance: 0; end gap separation penalty: on. An unrooted phylogenetic tree was constructed using
Neighbor-Joining (NJ) methods and bootstrapped with 1,000 iterations to help identify WRKY protein groups.

\section{Plant materials}

'Muscat Hamburg' ( $V$. vinifera) was obtained from the Institute of Botany, the Chinese Academy of Sciences. Tissues of young leaves, mature leaves, tendril, stem apex, root, young fruits and ripe fruits were collected from the vineyard in July, 2012. Cold and exogenous ABA treatment experiments were performed on tissue culture seedlings of 'Muscat Hamburg' according to Li et al. [62]. Briefly, seedlings were cultured on $1 / 2$ B5 medium with $30 \mathrm{~g} / \mathrm{L}$ of sucrose in a growth chamber under 16 -h light/8-h dark photoperiod at $26^{\circ} \mathrm{C}$. Cold treatments were performed in another growth chamber with the same parameters except for temperature $\left(4^{\circ} \mathrm{C}\right)$. Seedlings with five well developed leaves were used and the shoot apex with one well developed leaf was collected at 0 hour (h, used as control), $8 \mathrm{~h}, 24 \mathrm{~h}$ and $48 \mathrm{~h}$. Seedlings with five well developed leaves were transplanted in 1/2 B5 nutrient solution. Exogenous ABA treatments were performed after one week under normal culture conditions with $100 \mu \mathrm{M} \mathrm{ABA}$ and the shoot apex with one well developed leaves were collected at $0 \mathrm{~h}$ (used as control), $0.5 \mathrm{~h}, 1 \mathrm{~h}$ and $2 \mathrm{~h}$ after treatments. Three independent replicates were collected for each time point and frozen in liquid nitrogen. Samples were then stored at $-80^{\circ} \mathrm{C}$ for the following RNA isolation.

\section{Expression patterns analysis of VvWRKYs by RT-PCR}

Total RNA was isolated from collected samples using Plant Total RNA Isolation kit (Tiandz Inc; Beijing, China). RNase-free DNase (RQ1, Promega) was used to degrade DNA from total RNA. cDNA was synthesized by the SuperScript III Reverse Transcriptase (Invitrogen) with Oligo $(\mathrm{dT})_{18}$ (Promega) according to the manufacturer's instructions. Primer pairs (Additional file 7: Table S3) for $V v W R K Y$ s were designed by Primer 3 (http://bioinfo.ut.ee/primer3-0.4.0/) and tested by NCBI Primer BLAST. Two genes, $\beta$-actin (GenBank accession: EC969944; sense primer: 5'-CTTGCATCCCTCAGC ACCTT-3'; antisense primer: 5'-TCCTGTGGACAAT GGATGGA-3') and malate dehydrogenase gene (MDH; GenBank accession: EC921711; sense primer: 5'-CCAT GCATCACCCACAA-3'; antisense primer: 5'-GTCAA CCATGCTACTGTCAAAACC-3') were used as positive control for RT-CR [63]. Three biological replicate and 35 cycles for each reaction were performed. PCR products were detected by agarose gel electrophoresis with $2.5 \%$ gel concentration.

\section{Gene-chip based expression pattern analysis of VvWRKYs}

We explored the expression profiles of $V v W R K Y \mathrm{~s}$ using publically available data from the $16 \mathrm{k}$ Affymetrix $V$. 
vinifera gene-chip stored at PLEXdb (Plant Expression Database) [64] to explore the response of $V v W R K Y \mathrm{~s}$ during biotic and abiotic stresses in grape. The different studies and datasets that were included in these analyses were: A) a short term abiotic stress experiment in 'Cabernet Sauvignon' [39], B) a long-term salt and water stress study [65]; C) a study examining gene expression associated with compatible viral diseases in grapevine cultivars [66]; D) an experiment designed to examine the powdery mildew-induced transcriptome in a susceptible grapevine 'Cabernet Sauvignon' [67]; E) the complimentary dataset of the powdery mildew-induced transcriptome of a resistant grapevine 'Norton' [67]; F) a study of gene expression in grapevine in response to Bois noir infection [68]; G) a study of the grape skin transcriptome of berries grown on an exogenous abscisic acid treated vine [69]; H) the complimentary dataset of the grape skin transcriptome in the berries cultured in vitro and treated with exogenous ABA [69]; and lastly, I) a gene expression study associated with compatible viral diseases in the berry [70]. In our comparative analysis, we divided these experiments into either abiotic or biotic stresses related datasets. For each microarray experiment, the Affymetrix MAS5.0 normalized data were used for calculations of the fold change of differentially expressed genes. Probe sets corresponding to the putative $V v W R K Y \mathrm{~s}$ were identified at PLANEX (http://planex.plantbioinformatics.org) and completed via PLEXdb blast tool. Comparisons of WRKY expression level from gene-chip data for the short term abiotic stress treatment in 'Cabernet Sauvignon' was performed using Cluster 3.0 and JavaTreeview.

\section{Quantitative RT-PCR}

Total RNA was isolated from cold and exogenous ABA treated shoot apices following the cDNA synthesis methods mentioned above. Synthesized cDNA was diluted 1:10 with $\mathrm{ddH}_{2} \mathrm{O}$, and the quantitative RT-PCR reaction mixture contained $5 \mu \mathrm{l}$ of $2 \times \mathrm{SYBR}$ Green I Master Mix (Roche, USA), $2.6 \mu \mathrm{L} \mathrm{dd}_{2} \mathrm{O}, 0.2 \mu \mathrm{L}$ of $10 \mu \mathrm{M}$ solution of each primer and $2 \mu \mathrm{L}$ diluted template cDNA. Reaction specificities for each primer pair was tested using qRT-PCR melting curve analysis. The experiment was carried out using a StepOnePlus realtime PCR Instrument (Applied Biosystems). Transcription levels of each $V v W R K Y$ was normalized against the average of $\beta$-actin, MDH (as mentioned above) and glyceraldehyde-3-phosphatedehydrogenase (GAPDH: CB973647; sense primer: 5'-TTCTCGTTGAGGGCT ATTCCA-3'; antisense primer: 5'-CCACAGACTTCAT CGGTGACA-3') [63]. Each sample had three biological and two technical replicates to ensure the accuracy of results, and RNA samples with the same reversetranscription (without Reverse Transcriptase) and dilution procedure were used as negative controls. The $\mathrm{Ct}$ values and the real-time PCR efficiencies were obtained using Lin-RegPCR [71] and the normalized relative quantities and standard errors for each sample were calculated by qbaseplus [72]. The relative expression level of each $V v W R K Y$ in different templates was calculated based on normalized relative quantities. We used One-Way ANOVA analysis to test the impact of timing of cold treatment. When the effects were significantly different, we examined the difference between treatments using post hoc multiple comparisons (LSD, $p<0.05$ ). All data analyses were conducted using IBM SPSS Statistics 20.

\section{Additional files}

Additional file 1: Figure S1. Chromosomal location of 57 VWWRKYS. VVWRKYO3 was located on 'chromosome 1 random' and VVWRKYO4 was located on 'chromosome unknown'. Neither was shown here.

Additional file 2: Figure S2. The models of conserved amino acid sequences of WRKY domain and zinc-finger structure in four groups. The numbers behind the charts indicated gene numbers in each group.

Additional file 3: Table S1. The coefficient of variation of the corresponding treatment means (CV) and probe set IDs of VVWRKYs in 9 experiments. A higher CV means the expression of the probe set (gene) is affected by treatments in an experiment. Five VVWRKYs that didn't show any changes in any treatments are marked by green color.

Additional file 4: Table S2. Cold stress-related VVWRKYS obtained in one of three experimental methods. Yellow, red and blue forms represent genes obtained via qRT-PCR, gene-chip data and transcriptome data respectively. Exogenous ABA induced VWWRKYS were shown in green color in form.

Additional file 5: Figure S3. Quantitative RT-PCR assays of the expression level of $18 \mathrm{~V}$ VWRKYS under cold treatment. The transcription level of these genes didn't show significant changes during cold treatment in $V$. vinifera.

Additional file 6: Figure S4. Quantitative RT-PCR assays of the expression patterns of 44 VWWRKYs under exogenous ABA treatment. The transcription level of these genes didn't show significant changes during exogenous ABA treatment in $V$. vinifera.

Additional file 7: Table S3. The primers used for expression pattern analysis for $V W W R K Y$ S

\section{Abbreviations}

ABA: Abscisic acid.

\section{Competing interest}

The authors declare that they have no competing interests.

\section{Authors' contributions}

HPX, LNW, SHL and JPL designed and oversaw the research. LNW, LCF, XMS, LYS, ZCL and NW performed the research. LNW and WZ performed bioinformatics analysis, including gene identification and microarray data analysis. LNW, HPX, JPL and SHL wrote the article. All authors read and approved the final manuscript.

\section{Acknowledgments}

The authors thank Professor Yuepeng Han (Key Laboratory of Plant Germplasm Enhancement and Specialty Agriculture, Wuhan Botanical Garden, The Chinese Academy of Sciences) for critical review of this manuscript. This work was supported by the National Natural Science Foundation of China (NSFC Accession No.: 31130047, 31000902).

\section{Author details}

${ }^{1}$ Key Laboratory of Plant Germplasm Enhancement and Specialty Agriculture, Wuhan Botanical Garden, The Chinese Academy of Sciences, Wuhan, PR China. 
${ }^{2}$ Beijing Key Laboratory of Grape Sciences and Enology, Laboratory of Plant Resources, Institute of Botany, The Chinese Academy of Sciences, Beijing, PR China. ${ }^{3}$ University of Chinese Academy of Sciences, Beijing, PR China. ${ }^{4}$ United States Department of Agriculture-Agriculture Research Service, Grape Genetics Research Unit, Geneva, NY, USA

Received: 25 December 2013 Accepted: 11 April 2014

Published: 22 April 2014

\section{References}

1. Ulker B, Somssich IE: WRKY transcription factors: from DNA binding towards biological function. Curr Opin Plant Biol 2004, 7(5):491-498.

2. Rushton PJ, Somssich IE, Ringler P, Shen QXJ: WRKY transcription factors. Trends Plant Sci 2010, 15(5):247-258.

3. Ishiguro S, Nakamura K: Characterization of a CDNA encoding a novel DNA-binding protein, SPF1, that recognizes SP8 sequences in the $5^{\prime}$ upstream regions of genes coding for sporamin and beta-amylase from sweet potato. Mol Gen Genet 1994, 244(6):563-571.

4. Rushton PJ, Macdonald H, Huttly AK, Lazarus CM, Hooley R: Members of a new family of DNA-binding proteins bind to a conserved cis-element in the promoters of alpha-Amy2 genes. Plant Mol Biol 1995, 29(4):691-702.

5. Rushton PJ, Torres JT, Parniske M, Wernert P, Hahlbrock K, Somssich IE: Interaction of elicitor-induced DNA-binding proteins with elicitor response elements in the promoters of parsley PR1 genes. Embo J 1996, 15(20):5690-5700.

6. Ross CA, Liu Y, Shen QXJ: The WRKY gene family in rice (Oryza sativa). $J$ Integr Plant Biol 2007, 49(6):827-842.

7. Zhang YJ, Wang LJ: The WRKY transcription factor superfamily: its origin in eukaryotes and expansion in plants. BMC Evol Biol 2005, 5:1.

8. Rushton DL, Tripathi P, Rabara RC, Lin J, Ringler P, Boken AK, Langum TJ, Smidt L, Boomsma DD, Emme NJ, Chen X, Finer JJ, Shen QJ, Rushton PJ: WRKY transcription factors: key components in abscisic acid signalling. Plant Biotechnol J 2012, 10(1):2-11.

9. Eulgem T, Rushton PJ, Robatzek S, Somssich IE: The WRKY superfamily of plant transcription factors. Trends Plant Sci 2000, 5(5):199-206.

10. Xie Z, Zhang ZL, Zou XL, Huang J, Ruas P, Thompson D, Shen QJ: Annotations and functional analyses of the rice WRKY gene superfamily reveal positive and negative regulators of abscisic acid signaling in aleurone cells. Plant Physiol 2005, 137(1):176-189.

11. Eulgem T, Rushton PJ, Schmelzer E, Hahlbrock K, Somssich IE: Early nuclear events in plant defence signalling: rapid gene activation by WRKY transcription factors. Embo J 1999, 18(17):4689-4699.

12. Laloi C, Mestres-Ortega D, Marco Y, Meyer Y, Reichheld JP: The Arabidopsis cytosolic thioredoxin $\mathrm{h} 5$ gene induction by oxidative stress and its W-box-mediated response to pathogen elicitor. Plant Physiol 2004, 134(3):1006-1016.

13. Yang $P Z$, Chen $Z X: A$ family of dispersed repetitive DNA sequences in tobacco contain clusters of $W$-box elements recognized by pathogeninduced WRKY DNA-binding proteins. Plant Sci 2001, 161(4):655-664

14. Yamamoto S, Nakano T, Suzuki K, Shinshi H: Elicitor-induced activation of transcription via $W$ box-related cis-acting elements from a basic chitinase gene by WRKY transcription factors in tobacco. Bba-Gene Struct Expr 2004, 1679(3):279-287.

15. Wang Z, Zhu Y, Wang LL, Liu X, Liu YX, Phillips J, Deng X: A WRKY transcription factor participates in dehydration tolerance in Boea hygrometrica by binding to the W-box elements of the galactinol synthase (BhGolS1) promoter. Planta 2009, 230(6):1155-1166.

16. Mukhtar MS, Deslandes L, Auriac MC, Marco Y, Somssich IE: The Arabidopsis transcription factor WRKY27 influences wilt disease symptom development caused by Ralstonia solanacearum. Plant J 2008 , 56(6):935-947

17. Tao Z, Liu HB, Qiu DY, Zhou Y, Li XH, Xu CG, Wang SP: A Pair of Allelic WRKY Genes Play Opposite Roles in Rice-Bacteria Interactions. Plant Physiol 2009, 151(2):936-948.

18. Marchive C, Mzid R, Deluc L, Barrieu F, Pirrello J, Gauthier A, Corio-Costet MF, Regad F, Cailleteau B, Hamdi S, Lauvergeat V: Isolation and characterization of a Vitis vinifera transcription factor, VuWRKY1, and its effect on responses to fungal pathogens in transgenic tobacco plants. J Exp Bot 2007, 58(8):1999-2010.

19. Gallou A, Declerck S, Cranenbrouck S: Transcriptional regulation of defence genes and involvement of the WRKY transcription factor in arbuscular mycorrhizal potato root colonization. Funct Integr Genomics 2012, 12(1):183-198.

20. Yang $P Z$, Chen $C H$, Wang $Z P$, Fan BF, Chen $Z X$ : A pathogen- and salicylic acid-induced WRKY DNA-binding activity recognizes the elicitor response element of the tobacco class I chitinase gene promoter. Plant J 1999, 18(2):141-149.

21. Wang YN, Dang FF, Liu ZQ, Wang X, Eulgem T, Lai Y, Yu L, She JJ, Shi YL, Lin JH, Chen CC, Guan DY, Qiu A, He SL: CaWRKY58, encoding a group I WRKY transcription factor of Capsicum annuum, negatively regulates resistance to Ralstonia solanacearum infection. Mol Plant Pathol 2013, 14(2):131-144

22. Zhou XF, Wang GD, Sutoh K, Zhu JK, Zhang WX: Identification of coldinducible microRNAs in plants by transcriptome analysis. Bba-Gene Regul Mech 2008, 1779(11):780-788.

23. Zou CS, Jiang WB, Yu DQ: Male gametophyte-specific WRKY34 transcription factor mediates cold sensitivity of mature pollen in Arabidopsis. J Exp Bot 2010, 61(14):3901-3914.

24. Jiang YQ, Deyholos MK: Functional characterization of Arabidopsis $\mathrm{NaCl}$ inducible WRKY25 and WRKY33 transcription factors in abiotic stresses. Plant Mol Biol 2009, 69(1-2):91-105.

25. Wu XL, Shiroto Y, Kishitani S, Ito Y, Toriyama K: Enhanced heat and drought tolerance in transgenic rice seedlings overexpressing OsWRKY11 under the control of HSP101 promoter. Plant Cell Rep 2009, 28(1):21-30.

26. Ren XZ, Chen ZZ, Liu Y, Zhang HR, Zhang M, Liu QA, Hong XH, Zhu JK, Gong $Z Z: A B O 3$, a WRKY transcription factor, mediates plant responses to abscisic acid and drought tolerance in Arabidopsis. Plant J 2010, 63(3):417-429.

27. Jiang YJ, Liang G, Yu DQ: Activated expression of WRKY57 confers drought tolerance in Arabidopsis. Mol Plant 2012, 5(6):1375-1388.

28. Shen HS, Liu CT, Zhang Y, Meng XP, Zhou X, Chu CC, Wang XP: OsWRKY30 is activated by MAP kinases to confer drought tolerance in rice. Plant Mol Biol 2012, 80(3):241-253.

29. Mzid R, Marchive C, Blancard D, Deluc L, Barrieu F, Corio-Costet MF, Drira N, Hamdi S, Lauvergeat V: Overexpression of VvWRKY2 in tobacco enhances broad resistance to necrotrophic fungal pathogens. Physiol Plant 2007, 131(3):434-447.

30. Laquitaine L, Gomes E, Francois J, Marchive C, Pascal S, Hamdi S, Atanassova $R$, Delrot S, Coutos-Thevenot P: Molecular basis of ergosterol-induced protection of grape against Botrytis cinerea: Induction of type I LTP promoter activity, WRKY, and stilbene synthase gene expression. Mol Plant Microbe In 2006, 19(10):1103-1112

31. Guillaumie S, Mzid R, Mechin V, Leon C, Hichri I, Destrac-Irvine A, TrossatMagnin C, Delrot S, Lauvergeat $\mathrm{V}$ : The grapevine transcription factor WRKY2 influences the lignin pathway and xylem development in tobacco. Plant Mol Biol 2010, 72(1-2):215-234.

32. Li HE, Xu Y, Xiao Y, Zhu ZG, Xie XQ, Zhao HQ, Wang YJ: Expression and functional analysis of two genes encoding transcription factors, VpWRKY1 and VpWRKY2, isolated from Chinese wild Vitis pseudoreticulata. Planta 2010, 232(6):1325-1337.

33. Zhu ZG, Shi JL, Cao JL, He MY, Wang YJ: VpWRKY3, a biotic and abiotic stress-related transcription factor from the Chinese wild Vitis pseudoreticulata. Plant Cell Rep 2012, 31(11):2109-2120.

34. Liu HY, Yang WL, Liu DC, Han YP, Zhang AM, Li SH: Ectopic expression of a grapevine transcription factor VvWRKY11 contributes to osmotic stress tolerance in Arabidopsis. Mol Biol Rep 2011, 38(1):417-427.

35. Yu Y, Xu W, Wang J, Wang L, Yao W, Yang Y, Xu Y, Ma F, Du Y, Wang Y: The Chinese wild grapevine (Vitis pseudoreticulata) E3 ubiquitin ligase Erysiphe necator-induced RING finger protein 1 (EIRP1) activates plant defense responses by inducing proteolysis of the VpWRKY11 transcription factor. New Phytol 2013, 200(3):834-846.

36. Xin H, Zhu W, Wang L, Xiang Y, Fang L, Li J, Sun X, Wang N, Londo JP, Li S Genome wide transcriptional profile analysis of Vitis amurensis and Vitis vinifera in response to cold stress. PLos One 2013, 8(3):e58740.

37. Jaillon O, Aury JM, Noel B, Policriti A, Clepet C, Casagrande A, Choisne N, Aubourg S, Vitulo N, Jubin C, Vezzi A, Legeai F, Hugueney P, Dasilva C, Horner D, Mica E, Jublot D, Poulain J, Bruyère C, Billault A, Segurens B, Gouyvenoux M, Ugarte E, Cattonaro F, Anthouard V, Vico V, Fabbro CD, Alaux M, Gaspero GD, Dumas V, et al: The grapevine genome sequence suggests ancestral hexaploidization in major angiosperm phyla. Nature 2007, 449(7161):463-467.

38. Wu KL, Guo ZJ, Wang HH, Li J: The WRKY family of transcription factors in rice and Arabidopsis and their origins. DNA Res 2005, 12(1):9-26. 
39. Tattersall EA, Grimplet J, DeLuc L, Wheatley MD, Vincent D, Osborne C, Ergul A, Lomen E, Blank RR, Schlauch KA, Cushman JC, Cramer GR: Transcript abundance profiles reveal larger and more complex responses of grapevine to chilling compared to osmotic and salinity stress. Funct Integr Genomics 2007, 7(4):317-333.

40. Ling J, Jiang WJ, Zhang Y, Yu HJ, Mao ZC, Gu XF, Huang SW, Xie BY: Genome-wide analysis of WRKY gene family in Cucumis sativus. BMC Genomics 2011, 12:471.

41. Li HL, Zhang LB, Guo D, Li CZ, Peng SQ: Identification and expression profiles of the WRKY transcription factor family in Ricinus communis. Gene 2012, 503(2):248-253.

42. Tripathi $P$, Rabara RC, Langum TJ, Boken AK, Rushton DL, Boomsma DD, Rinerson Cl, Rabara J, Reese RN, Chen XF, Rohila JS, Rushton PJ: The WRKY transcription factor family in Brachypodium distachyon. BMC Genomics 2012, 13:270.

43. Wei KF, Chen J, Chen YF, Wu LJ, Xie DX: Molecular phylogenetic and expression analysis of the complete WRKY transcription factor family in maize. DNA Res 2012, 19(2):153-164.

44. Lee $T H$, Tang H, Wang X, Paterson AH: PGDD: a database of gene and genome duplication in plants. Nucleic Acids Res 2013, 41(Database issue): D1152-D1158.

45. Kalde M, Barth M, Somssich IE, Lippok B: Members of the Arabidopsis WRKY group III transcription factors are part of different plant defense signaling pathways. Mol Plant Microbe Interact 2003, 16(4):295-305.

46. Wang NA, Xiang Y, Fang LC, Wang YJ, Xin HP, Li SH: Patterns of gene duplication and their contribution to expansion of gene families in grapevine. Plant Mol Biol Report 2013, 31(4):852-861.

47. Gregersen PL, Holm PB: Transcriptome analysis of senescence in the flag leaf of wheat (Triticum aestivum L.). Plant Biotechnol J 2007, 5(1):192-206.

48. Zhang CQ, Xu Y, Lu Y, Yu HX, Gu MH, Liu QQ: The WRKY transcription factor OsWRKY78 regulates stem elongation and seed development in rice. Planta 2011, 234(3):541-554.

49. Yu FF, Huaxia YF, Lu WJ, Wu CG, Cao XC, Guo XQ: GhWRKY15, a member of the WRKY transcription factor family identified from cotton (Gossypium hirsutum L.), is involved in disease resistance and plant development. BMC Plant Biol 2012, 12:144.

50. Knight $H$, Knight MR: Abiotic stress signalling pathways: specificity and cross-talk. Trends Plant Sci 2001, 6(6):262-267.

51. Park CY, Lee JH, Yoo JH, Moon BC, Choi MS, Kang YH, Lee SM, Kim HS, Kang $K Y$, Chung WS, Lim CO, Cho MJ: WRKY group Ild transcription factors interact with calmodulin. Febs Lett 2005, 579(6):1545-1550.

52. Zhang JZ, Creelman RA, Zhu JK: From laboratory to field. Using information from Arabidopsis to engineer salt, cold, and drought tolerance in crops. Plant Physiol 2004, 135(2):615-621.

53. Yan L, Liu ZQ, Xu YH, Lu K, Wang XF, Zhang DP: Auto- and crossrepression of three Arabidopsis WRKY transcription factors WRKY18, WRKY40, and WRKY60 negatively involved in ABA signaling. J Plant Growth Regul 2013, 32(2):399-416.

54. Medina J, Catala R, Salinas J: The CBFs: three Arabidopsis transcription factors to cold acclimate. Plant Sci 2011, 180(1):3-11.

55. Huang T, Duman JG: Cloning and characterization of a thermal hysteresis (antifreeze) protein with DNA-binding activity from winter bittersweet nightshade, Solanum dulcamara. Plant Mol Biol 2002, 48(4):339-350.

56. Mare C, Mazzucotelli E, Crosatti C, Francia E, Stanca AM, Cattivelli L: Hv-WRKY38: a new transcription factor involved in cold- and droughtresponse in barley. Plant Mol Biol 2004, 55(3):399-416.

57. Wang F, Hou XL, Tang J, Wang Z, Wang SM, Jiang FL, Li Y: A novel coldinducible gene from Pak-choi (Brassica campestris ssp chinensis), BcWRKY46, enhances the cold, salt and dehydration stress tolerance in transgenic tobacco. Mol Biol Rep 2012, 39(4):4553-4564.

58. Shekhawat UKS, Ganapathi TR, Srinivas L: Cloning and characterization of a novel stress-responsive WRKY transcription factor gene (MusaWRKY71) from Musa spp. cv. Karibale Monthan (ABB group) using transformed banana cells. Mol Biol Rep 2011, 38(6):4023-4035.

59. Altschul SF, Madden TL, Schaffer AA, Zhang J, Zhang Z, Miller W, Lipman DJ: Gapped BLAST and PSI-BLAST: a new generation of protein database search programs. Nucleic Acids Res 1997, 25(17):3389-3402

60. Arnold K, Bordoli L, Kopp J, Schwede T: The SWISS-MODEL workspace: a web-based environment for protein structure homology modelling. Bioinformatics 2006, 22(2):195-201.
61. Tamura K, Peterson D, Peterson N, Stecher G, Nei M, Kumar S: MEGA5: molecular evolutionary genetics analysis using maximum likelihood, evolutionary distance, and maximum parsimony methods. Mol Biol Evol 2011, 28(10):2731-2739.

62. Li J, Wang N, Xin H, Li S: Overexpression of VaCBF4, a Transcription Factor from Vitis amurensis, Improves Cold Tolerance Accompanying Increased Resistance to Drought and Salinity in Arabidopsis. Plant Mol Biol Report 2013, 31(6):1518-1528.

63. Reid KE, Olsson N, Schlosser J, Peng F, Lund ST: An optimized grapevine RNA isolation procedure and statistical determination of reference genes for real-time RT-PCR during berry development. Bmc Plant Biol 2006, 6:27.

64. Dash S, Van Hemert J, Hong L, Wise RP, Dickerson JA: PLEXdb: gene expression resources for plants and plant pathogens. Nucleic Acids Res 2012, 40(Database issue):D1194-D1201.

65. Cramer GR, Ergul A, Grimplet J, Tillett RL, Tattersall EAR, Bohlman MC, Vincent D, Sonderegger J, Evans J, Osborne C, Quilici D, Schlauch KA, Schooley DA, Cushman JC: Water and salinity stress in grapevines: early and late changes in transcript and metabolite profiles. Funct Integr Genomics 2007, 7(2):111-134

66. Espinoza C, Vega A, Medina C, Schlauch K, Cramer G, Arce-Johnson P: Gene expression associated with compatible viral diseases in grapevine cultivars. Funct Integr Genomics 2007, 7(2):95-110.

67. Fung RWM, Gonzalo M, Fekete C, Kovacs LG, He Y, Marsh E, McIntyre LM, Schachtman DP, Qiu WP: Powdery mildew induces defense-oriented reprogramming of the transcriptome in a susceptible but not in a resistant grapevine. Plant Physiol 2008, 146(1):236-249.

68. Albertazzi G, Milc J, Caffagni A, Francia E, Roncaglia E, Ferrari F, Tagliafico E, Stefani E, Pecchioni N: Gene expression in grapevine cultivars in response to Bois Noir phytoplasma infection. Plant Sci 2009, 176(6):792-804.

69. Koyama K, Sadamatsu K, Goto-Yamamoto N: Abscisic acid stimulated ripening and gene expression in berry skins of the Cabernet Sauvignon grape. Funct Integr Genomics 2010, 10(3):367-381.

70. Vega A, Gutierrez RA, Pena-Neira A, Cramer GR, Arce-Johnson P: Compatible GLRaV-3 viral infections affect berry ripening decreasing sugar accumulation and anthocyanin biosynthesis in Vitis vinifera. Plant $\mathrm{Mol}$ Biol 2011, 77(3):261-274.

71. Ruijter JM, Ramakers C, Hoogaars WM, Karlen Y, Bakker O, van den Hoff MJ, Moorman AF: Amplification efficiency: linking baseline and bias in the analysis of quantitative PCR data. Nucleic Acids Res 2009, 37(6):e45.

72. Hellemans J, Mortier G, De Paepe A, Speleman F, Vandesompele J: qBase relative quantification framework and software for management and automated analysis of real-time quantitative PCR data. Genome Biol 2007, 8(2):R19.

doi:10.1186/1471-2229-14-103

Cite this article as: Wang et al:: Genome-wide identification of WRKY

family genes and their response to cold stress in Vitis vinifera. BMC Plant Biology 2014 14:103.

\section{Submit your next manuscript to BioMed Central and take full advantage of:}

- Convenient online submission

- Thorough peer review

- No space constraints or color figure charges

- Immediate publication on acceptance

- Inclusion in PubMed, CAS, Scopus and Google Scholar

- Research which is freely available for redistribution 